\title{
Mapping National Qualifications Frameworks and Awards using MapQFTool
}

\author{
Philippos Pouyioutas, Harald Gjermundrod, Ioanna Dionysiou, and Michalis Michael \\ Department of Computer Science,University of Nicosia \\ Nicosia, Cyprus
}

\begin{abstract}
This paper presents MapQFTool, a software tool that provides support to the understanding and comparability of the National Qualifications Frameworks (NQFs) of the European countries. The paper starts by providing background information on the Bologna Process and the Qualifications Frameworks. It then addresses the limitations of trying to map the various NQFs against the European Qualifications Framework (EQF), and through the EQF against each other and explains the advantages of automating this process using a software tool. The paper finally presents the tool and its functionality; this is done by giving the design of the underlying database, sample data using two $N Q F$ s, sample queries and their results, as well as its system architecture and development platform. We argue that MapQFTool will be a very useful asset to all stakeholders, namely the European Commission, the National Quality Assurance Agencies of all European (and not only) countries, the educational institutions, the Ministries of Education and Labour, prospective students, students, employers, careers officers, Erasmus co-ordinators and the general public.
\end{abstract}

\section{Introduction}

The Bologna process [1] aims at developing a European Educational Framework of standards, definitions and concepts so as to provide the basis for European countries to transform their educational system according to this framework. This will result in comparability/compatibility of the various European educational systems which will then yield collaborations amongst educational institutions, exchanges of students and teachers within Europe and transparency and transferability of qualifications, all being very important when looked from the point of view of students, Erasmus co-coordinators, prospective employers, Quality Assurance Agencies (QAAs), European Network of Information Centres (ENIC), and National Academic Recognition Information Centres (NARIC).

The European Qualifications Framework [2][3] provides the basis for mapping the National Qualifications Framework (NQF) of each European country against this framework, thus transitively, mapping each country's educational system against another country's system. EQF and NQFs describe in terms of Learning Outcomes (knowledge, skills, competences) the various levels of education starting from the pre-primary level and reaching the doctorate level. EQF caters for eight such levels, whereas NQFs may cater a different number of levels. Eight European countries have already developed their NQF; among these are: Denmark, Ireland, Malta, and United Kingdom. Examples of NQFs can be found in [4-6], whereas a report on the progress of various countries with regards to the development of the NQF can be found in [7].

It is expected that most of the countries that have not developed their NQF, will do so by the end of 2012. Thus, although the setting up of all NQFs in Europe, the mapping of the awards against the NQFs levels and of the NQFs levels against the EQF levels have not been completed, it is anticipated that a manual process for producing information will be laborious, slow and prone to errors.

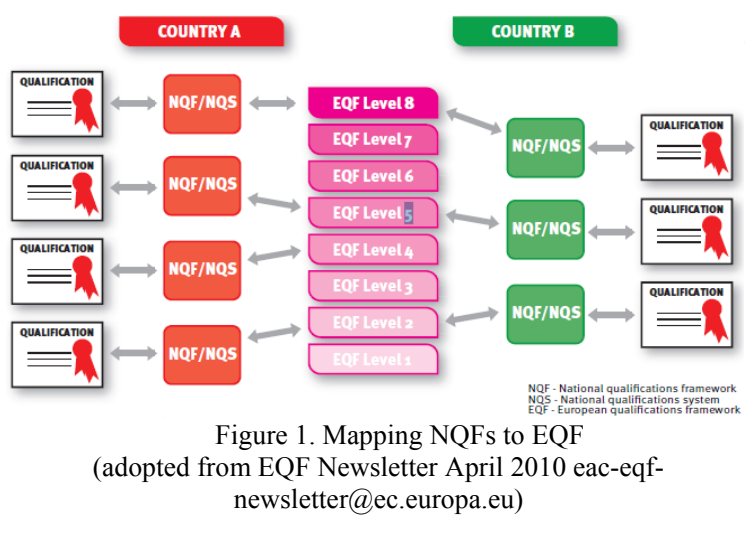

Many European countries may opt to adopt the eight levels of EQF into their NQF (e.g. Malta NQF, UK NQF), thus providing a one-to-one relationship with EQF levels. Irrespectively of whether eight or more or fewer levels are adopted in a NQF, a mapping should be provided from the NQF to EQF allowing one to understand at which European level a national qualification level (and thus an award of that level) corresponds to. The mappings of all NQFs to $\mathrm{EQF}$ will subsequently allow transitively a mapping from one NQF against another and thus an understanding of different educational systems of countries and equivalence of levels and awards/degrees across Europe (Figure 1). This is tremendously essential for students, academic 
institutions, employers and National Quality Assurance Agencies.

This paper presents the prototype implementation of MapQFTool. The initial design of the tool has already been presented in $[8,9]$. Our research work in the area of utilizing Information Communication Technology in reforming the European higher education has also been presented in [10-16]. Our work is in line with the European Commission's 2007 Communication "e-Skills for the 21st Century: Fostering Competitiveness, Growth and Jobs" $[17,18]$ and can relate to the European e-Competence Framework [19] and the work carried out within the CEN Workshop on ICT Skills [20].

The rest of this paper is organized as follows. Section 2 explains the need for MapQFTool. Section 3 describes the users and the tool's functionality, along with sample usage scenarios. Section 4 provides design and implementation details such as the platform used to develop the tool. Section 5 presents our future work with regards to the evaluation of the proposed tool. Finally, Section 6 presents our concluding remarks.

\section{The Need for MapQFTool}

The proposed software tool aims in presenting in an easy and intuitive manner information to the various stakeholders. More specifically, the European Commission Agency responsible for EQF, Educational Institutions and National Quality Assurance Agencies in all European countries will be maintaining the database that will support the tool. Information regarding programmes of studies/awards offered by the institutions/countries, the NQF levels of each European country, the mapping of each award to the appropriate NQF level and the mapping of each NQF level to the appropriate EQF level will be residing in the database. This raw data will then be used to produce useful information for all the aforementioned stakeholders, as well as to ministries of education, students, parents, employers and the general public. More specific details as to who is responsible for what part of the database data is given in Section 3.

Although the setting up of all NQFs in Europe and the mapping of the awards against the NQFs levels and of the NQFs levels against the EQF levels has not been completed, it is expected that a manual process for producing information will be laborious, slow and prone to errors. On the contrary, the use of the proposed tool will provide fast error-free information, as a result of either predefined or ad-hoc reports/queries. In particular, the tool will be supplying information to queries such as:

1. Given an award type, what is its NQF level in a given country

2. Given an award type, what is its EQF level
3. Given an award type in country A, what is its NQF level in country B

4. Given an award type in country A, what are the equivalent NQF levels in all other countries

5. Given an award type in country A what are its equivalent types of awards in country B

6. Given a qualification, what is its NQF level in a given country

7. Given a qualification, what is its EQF level

8. Given a qualification in country $\mathrm{A}$, what are its NQF levels in all other countries

9. Given a qualification in country A what are its equivalent qualifications in country $\mathrm{B}$

10. Given an NQF level in country A what is its equivalent $\mathrm{EQF}$ level

11. Given an NQF level in country A, what is its equivalent level in country $B$

12. Given an NQF level in country A, what are the equivalent NQF levels in all other countries

13. Given an EQF level what are/is the equivalent level(s) in the NQF of country A

14. Given an EQF level what are/is the awards of that level in country A

15. Given an EQF level what are/is the awards of that level in all countries

All the above queries are just samples of predefined inquiries that can be expressed in the database's query language/report writer and produce answers on the spot; they do not present the exhaustive list of information that could be generated by the system, but only samples that exemplify the functionality and usage of the tool.

\section{MapQFTool Users and Functionality}

MapQFTool, being a web-based application, is accessed over the Internet by the interested parties. Figure 2 depicts graphically prospective users of the tool. We will now explain the users of the tool and the way it functions in terms of write/read data access and authorization privileges.

Not all users should be allowed write access to the information. The appropriate access control mechanisms must be in place to restrict access to data based on the user's role in the overall system. For the time being, we consider read and write access permissions to the database information. Write access is restricted to the European Commission and the European NQAAs. The European commission is responsible for maintaining the data pertaining to the EQF and for creating and maintaining all the NQAAs. Similarly, each NQAA is responsible for maintaining the data pertaining the NQF, to the institutions of the country of the NQAA, 
its award types (along with their mappings to the appropriate EQF level) and the awards given by its institutions. Open access is supported for users such as students, educational institutions, ministries of education and labour, teachers as well as the general public such as parents and employers, who are able to obtain information similar to the one discussed in Section 2. In this way, the tool supports a role-based access control, with the three roles to be European Commission EQF, National QAA, and other. The latter role does not require any authentication credentials (user name and password) as it is for the general public, whereas the other roles will need to follow an authentication process.

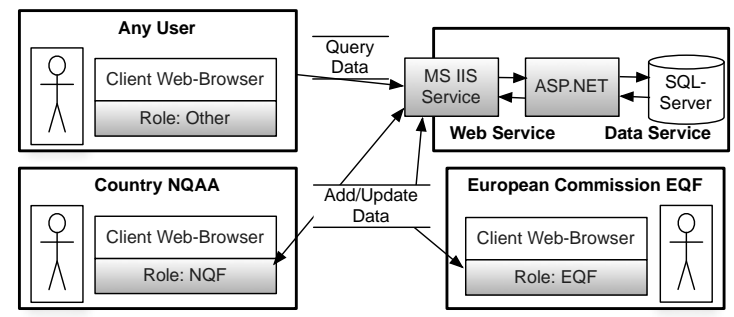

Figure 2. MapQFTool Architecture

In order to exemplify the functionality of the tool we present screenshots of the tool's interface when a user wants to find out information on comparable levels of NQFs and higher education types of awards in two different countries, namely Ireland and Cyprus. The reason these two countries serve in the example is twofold. First, the Irish NQF has 10 levels (as compared to 8 of the EQF) and additionally Irish Universities offer many different types of awards at the various levels of higher education. Second, the Cyprus NQF, although not yet fully developed, it will (based on the draft version) cater for 8 levels. Universities in Cyprus offer limited types of awards at the higher education

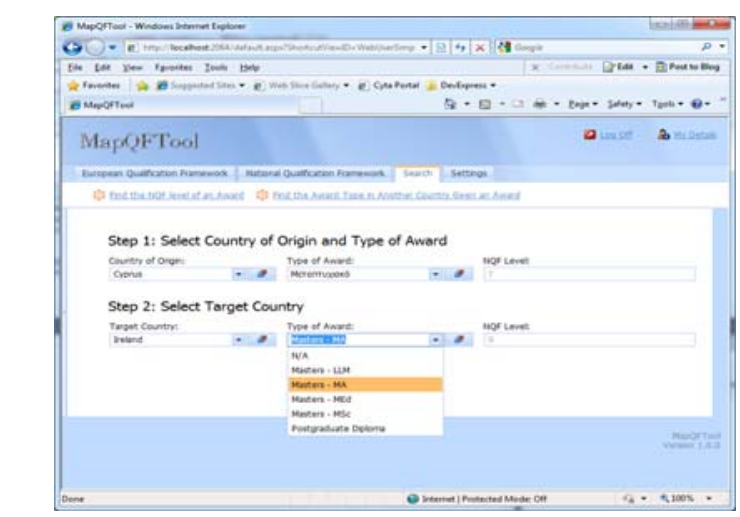

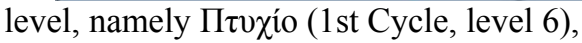

Figure 3. Mapping of Award Types in Different Countries

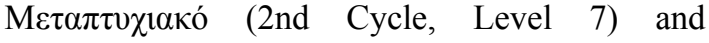

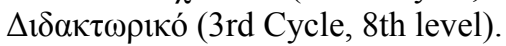

We will focus on level 9 of the Irish NQF, which is the Masters level (2nd Cycle) and corresponds to level 7 of the Cyprus NQF. At level 9 of the NQF, Irish Universities offer Masters Degrees and Postgraduate Diplomas. Masters degrees are offered in different subject areas and thus lead to different types of titles/awards (MSc, MA, MEng, LLM, MEd, etc.). Therefore, in this example, there are awards in two different languages, mapped on different levels, and for one award in Cyprus there exist different equivalent types of awards in Ireland.

The screenshot of Figure 3 shows how the user (e.g. an employer in Ireland assessing a candidate

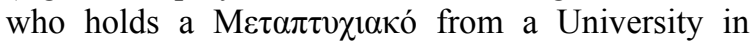
Cyprus) selects a country (from a the Country_of_Origin drop-down list giving all European countries - in this case Cyprus), then

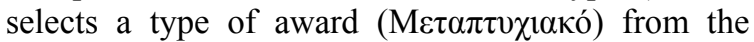
Type_of_Award drop-down list, and finally selects another country (in this case Ireland) from the Target_Country drop-down list. The system automatically shows the NQFs level equivalences (level 7 of Cyprus NQF and level 9 of Irish NQF) and then displays the list of all Irish equivalent types of awards (Postgraduate Diploma, Masters-MSc, Masters-MA, etc.).

This screen interface is provided for various users in more simplified forms allowing browsing such as: 1. select a country, select an award type and display the NQF level of the award type in that country

2. select a country, select an award type and display the EQF level of the award type

3. select the country of origin, select an award type, select another the target country and display the NQF level of the award type in the target country.

In a more complicated screen interface, users can query for a qualification awarded by an institution in Cyprus and find its equivalent NQF level and award type in Ireland. This needs another three drop-down lists, namely Institution_Type, Institution and Qualification, next to Country_of_Origin drop-down list. Once the user selects a country, s/he chooses a type of institution, then an institution, followed by a qualification awarded by the institution and finally the target country. The system then displays the equivalent NQF level and type of award in the target country. Figure 4 illustrates this functionality through an example of a user selecting "Cyprus" as the Country of Origin, "University" as the Type of Institution, "University of Cyprus" as the Institution,

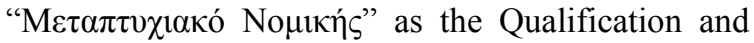
finally "Ireland" as the Target Country; the system then displays Level 7 for the Cyprus NQF, Level 9 for the Irish NQF and all the equivalent types of awards. 


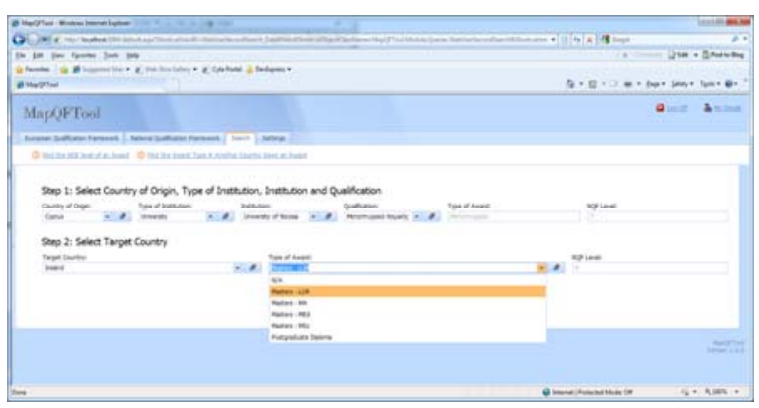

Figure 4. Mapping of Award in Different Countries

The screen interface above also exists in more simplified forms, allowing browsing such as:

1. select a country, select a type of institution, select an institution, select a qualification and display the NQF level of the qualification in that country

2. select a country, select a type of institution, select an institution, select a qualification and display the EQF level of the qualification

3. select the country of origin, select a type of institution, select an institution, select a qualification, select the target country and display the NQF level of the qualification in the target country.

\section{Design and Implementation of MapQFTool}

In this section we provide details on the development environment and architecture of the tool. The object model is presented along with the generated relational database that accommodates the system functionality as explained in the previous sections.

\subsection{Development Environment}

The MapEQFTool has been built using Microsoft's .NET platform with the DXperience tools provided by DevExpress. The .NET platform provides for rapid development and reuse of the .NET components like WYSIWYG (What You See Is What You Get), GUI building (web-forms), database connectors, and ASP.NET controls.

The DXperience tool is an add-on tool to the .NET framework and assists the developer in developing business applications. For this project two of the components provided by this tool were utilized, namely eXpress Application Framework (XAF) and Xpress Persistent Objects (XPO).

The XAF component uses the Model View Control (MVC) pattern and allows the developer to concentrate on the business logic of the application. Generally an application consists of Data Management, Validation, Analysis, Reporting,
Localisation and Security system, but these are all handled by the XAF.

The XPO component handles all aspects of database creation and object persistence. XPO is able to automatically map the properties of business objects to relational database tables. Hence, the developer is only concentrated on developing an object oriented business application and all the translation and storage details are handled by the XPO component of the DXperience tool.

\subsection{Architecture}

A 3-tier web application architecture has been used for the tool (see Figure 2). The information and request/reply flow between the three tiers is as follows: The user enters the web site using an Internet browser. The front-end web-service receives a request from the client browser, and this is forwarded to the web service, which queries the database and generates a webpage with the requested information that is then sent back to the user's browser. One of the benefits of this architecture is the clear separation among the presentation layer, application logic layer, and the data access layer. As the tool is a web service, users could access it from anywhere as long as they have access to an Internet browser. This simplifies the tool usage for the average user, as there will be no need to install any software on his/her personal computer.

\section{1) Presentation Layer}

The presentation layer provides the interface to the end-user. Depending on the role of the user the tool renders a customized webpage. From there, the user can access the data, customize queries on the data, and update the data, depending on the privileges of the assigned role. The users do not directly specify the database queries, but instead they choose from a set of predefined options and set parameters that automatically generate the specific queries. Hence, the technical knowledge required is kept at a minimum.

\section{2) Application Logic Layer}

The application layer performs the requested requests/actions from the users and returns the result back to them. It consists of two components, namely the front-end web-service and the ASP (Active Server Pages). For the front-end web-service, Microsoft's Internet Information Services (IIS) is used. The service concurrently accepts requests from multiple end-users and forwards these to the ASP components. Once the result is returned from ASP, the IIS service forwards the resulting web page to the appropriate end user. ASP components are 
responsible for performing the application logic of the clients' requests; some of them are "connected" with a GUI element within the web page. The result of the request is a webpage (HTML) that is sent back to the user. If the application logic needs data in order to generate a new web site, then it makes a request to the third tier to provide the required data.

\section{3) Data Access Layer}

The data access layer provides access to the back-end database that stores all the data. The database receives its queries from the ASP component as SQL queries and returns the resulting data, which is used to generate dynamic web pages that are forwarded to the user. The tool uses Microsofts SQLServer database for its back-end storage. SQLServer is a relational database management system (RDBMS) supporting T-SQL and ANSI SQL query languages. Connectors are provided to interact with SQLServer programmatically on the .NET platform.

\subsection{Object-Model and Derived Database}

Traditionally, the first step to be taken when developing a database application is to design the database schema, followed by developing the application using an object-oriented design. When data is to be retrieved or stored to the database, the data is extracted from the objects and SQL queries are executed to either retrieve or store data to the various tables. The .NET framework has build-in tools to ease the development of database applications by being able to extract from a database its organization and automatically generate the object model. This is helpful and eases the development, but the database must be designed first.

On the other hand, object-oriented design is becoming the popular way of developing applications, where the data is encapsulated by its functionality. In this paradigm, if data needs to be stored in a database, the object model must be converted in a way such that each class becomes a table and each class instance becomes a table row. In addition, the relationships between classes must also be converted to relations between tables.

The DXperience tool supports an object-oriented design perspective when developing software. The DXperience is an extension to the .NET framework that simplifies the task of developing database applications. The designer doesn't need to be concerned with the specifics of designing a database and specifying queries. The design of the application is done by using object-oriented principles. If the instances of a specific class need to be stored (to a database), then the only thing that must be done is to have the class inheriting from XPO (Xpress Persistent Objects) class. A schema for the database is generated automatically and the data the user enters in the application is stored automatically to the database.

Figure 5 illustrates the generated database schema for the MapQFTool that describes the database entities, relationships and relational tables (including primary and foreign keys). In order to verify that an acceptable schema is being generated, we also designed a database schema independently from the tool, and when compared they were actually the same.

\section{Deployment of MapQFTool}

Our future work entails the testing and Beta Release of the tool. Testing will be performed by various stakeholders. To this end, training seminars will be delivered to the users (Ministry of Education and Labour, NQAAs and NARIC/ENIC officials) who will evaluate the tool. The testing of MapQFTool will be performed in order to ensure that the system meets the user requirements and performs as expected, based on the analysis and design of the system. Testing is a very important aspect of the life-cycle of a software system and requires considerable time and investment. It will entail:

- Compliance testing will be done in order to test if the application conforms to the specification and expectation of the users.

- Functionality testing will be done in order to test if the functionality of the application works correctly.

- The documentation and help system will be tested to make sure that the instructions are complete and accurate, catch erroneous information, or ambiguous information.

Based on the feedback and the changes/improvements/corrections, MapQFTool will be enhanced resulting in the beta version of MapQFTool

Once the system is fine-tuned, it will be pilottested in various EU countries by ministries of Education and Labour, NQAAs, NARIC/ENIC, interested academics and selected students. During this stage, further feedback will be received and analyzed. Final changes/enhancements to the tool will be made based on this feedback and the first public release of the software tool will be made available. 


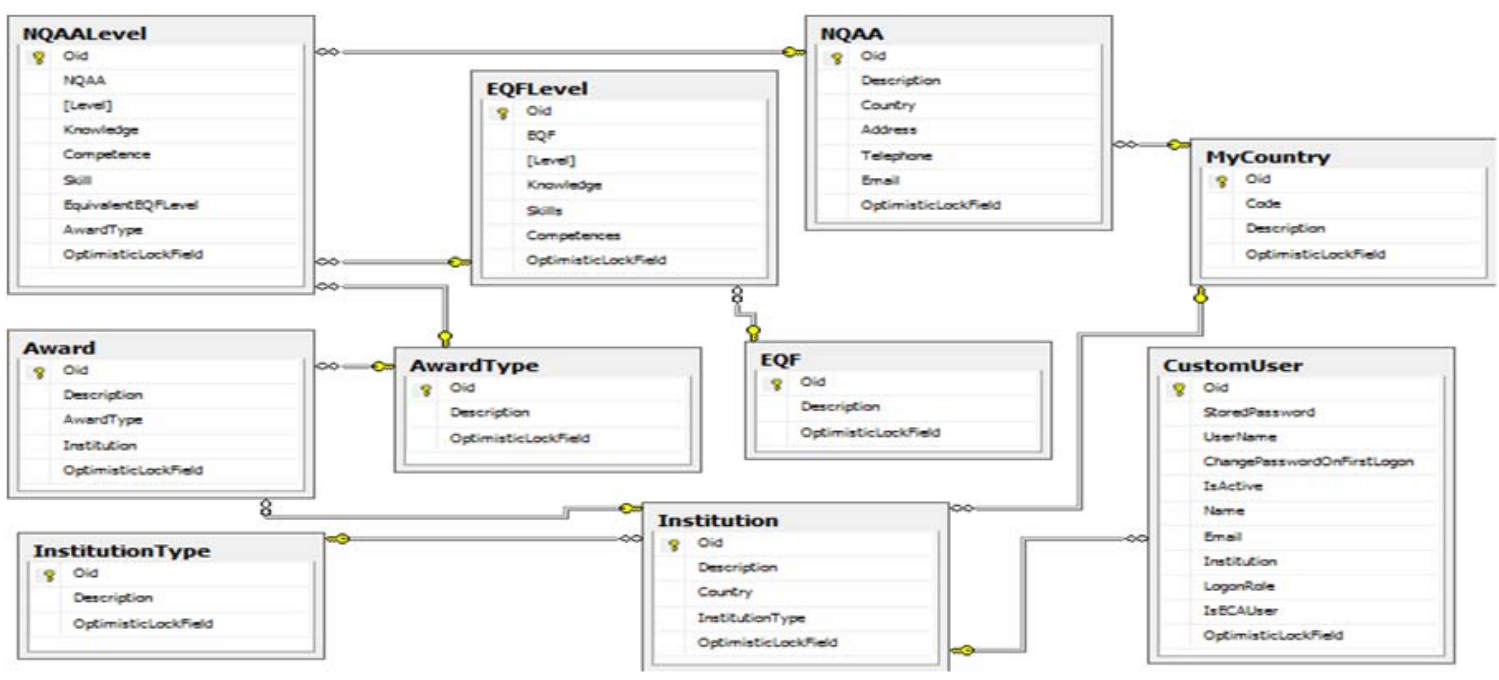

Figure 5. The Generated Database Scheme

\section{Conclusions}

This paper has presented the MapQFTool, which allows the various National Qualification Frameworks (NQFs) to be mapped against the European Qualification Framework and thus against each other. The need for the tool was discussed and justified by addressing the various limitations of carrying out manually this process and trying to compare and evaluate different qualifications and types of awards from different countries. To this end, we provided data and example queries to illustrate the functionality of the tool. Finally we presented the design and system architecture, elaborating on the platforms chosen for its development and deployment and explain how we will carry out the testing of the tool. We expect that MapQFTool will be a very useful asset to all stakeholders, namely the European Commission, the National Quality Assurance Agencies of all European (and not only) countries, the educational institutions, the Ministries of Education and Culture, prospective students, students, employers, careers officers, Erasmus coordinators and the general public.

\section{References}

[1] European Commission Education and Learning, "The Bologna Process",

http://ec.europa.eu/education/policies/educ/bologna/bologn a en.html.

[2] $\mathrm{EQF}$

2010

http://ec.europa.eu/dgs/education_culture/publ/pdf/eqf/bro ch_en.pdf
[3] EQF Newsletter 1, 2010 eac-eqfnewsletter@ec.europa.eu

[4] Ireland NQF, 2009 http://www.nqai.ie/documents/EQFReferencingReportfinal June2009.pdf

[5] Malta NQF, 2009

http://www.mqc.gov.mt/referencingreport?l=1

[6] UK NQF, 2010 http://www.qaa.ac.uk/academicinfrastructure/FHEQ/EWN I08/FHEQ08.pdf

[7] Bergan, S. "Sharing Experinecs in the Development of National Qualifications Frameworks", http://www.ehea.info/Uploads/Irina/BFUG_HU_AD_24_9 $.6 \mathrm{a} \% 20 \mathrm{QF} \% 20 \mathrm{WG} \% 20$ and\%20Network\%20update.pdf

[8] Pouyioutas P, Gjermundrod H, Dionysiou I and Michael M. (2011) "MapQFTool, A Software Tool to Support National Qualifications Frameworks", International Conference on i-Society, June 2011, UK.

[9] Pouyioutas P, Gjermundrod H, and Dionysiou I (2011) "The Development of the MapQFTool, A Software Tool for National Qualifications Frameworks" 3rd International Conference on Computer Supported Education, May 2011, Netherlands.

[10] Pouyioutas P "Hybrid Learning Curriculum Development Using the ReProTool - Lessons From Ancient Philosophy" International Conference on Hybrid Learning, ICHL2010, August 2010, China, LNCS 6248, pp. $160-170$

[11] Pouyioutas P, Gjermundrod H, and Dionysiou I (2010) "The Development of ReProTool, A Software Tool for Developing Programmes Using Learning Outcomes" IADIS International Conference e-Learning, Germany July 2010, Volume II, pp. 96-100

[12] Pouyioutas P, Gjermundrod H, and Dionysiou I (2010) "ReProTool Version 1.0 Managing Learning Outcomes - A Useful Tool for Erasmus Co-ordinators, Employers and ENIC/NARIC Networks", ERACON 2010, Austria, July 2010 , 
http://www.eracon.info/assets/files/2010/Full\%20Papers/P hilipposPouyioutas Cyprus.pdf

[13] Pouyioutas P, Gjermundrod H, and Dionysiou I (2010) "REPROTOOL Version 1.0, Support for Learning Outcomes", third award for best poster, Recognition in Higher Education - How to make it work!, Seminar by UNICA for the Bologna and Higher Education Reform Experts, Tallinn Estonia, June 2010, http://tallinn2010.bolognaexperts.net/sites/default/files/Pos ter_Cyprus_Pouyioutas.ppt

[14] Pouyioutas P, Gjermundrod H, and Dionysiou I (2010) "The Development of the TunTool, A Software Tool for the Tuning Methodology" 2nd International Conference on Computer Supported Education, April 2010, Spain, Volume II, pp. 401-406

[15] Pouyioutas P, Gjermundrod H, and Dionysiou I (2010) "ReProTool, A Software Tool for Managing Learning Outcomes" EUROPEAN CAREER Guidance Counselling Conference CAREER-EU 2010, Cyprus, May 2010, pp. 200-207

[16] Pouyioutas P (2009) "The Design of the TunTool, A Software Tool for the Tuning Methodology" IADIS International Conference on e-Society, Spain, February, 2009, Vol. 2, pp. 75-79.

[17] European Commission Communication: e-Skills for the 21st Century: Fostering Competitiveness, Growth and Jobs, http://ec.europa.eu/enterprise/sectors/ict/files/comm_pdf_c om_2007_0496_f_en_acte_en.pdf

[18] European Commission: e-skilss for the 21st Century, http://ec.europa.eu/enterprise/sectors/ict/e-skills/ [19] European e-Competence Framework, http://www.ecompetences.eu/

[20] CEN Workshop on ICT Skills, http://www.ecompetences.eu/2038,CEN+ICT+Skills+Wor kshop.html 